\title{
Baseline $\mathrm{E}_{2}$ Levels Are Higher in BRCA2 Mutation Carriers: A Potential Target for Prevention?
}

\author{
Jayeon $\mathrm{Kim}^{1}$ and Kutluk Oktay ${ }^{1, *}$ \\ ${ }^{1}$ Institute for Fertility Preservation and Department of Obstetrics and Gynecology, New York \\ Medical College, Rye, NY
}

\section{Abstract}

Purpose-BRCA gene mutations and elevated serum estradiol $\left(\mathrm{E}_{2}\right)$ are well-known risk factors for breast cancer. The aim of this study was to investigate the association between BRCA gene mutations and serum $\mathrm{E}_{2}$ level.

Methods-We measured baseline (menstrual cycle day 2-3) $\mathrm{E}_{2}$ levels of 96 women with breast cancer who underwent BRCA testing.

Results-The mean age, parity, and age at menarche did not differ between women with and without BRCA1/2 mutations. Basal serum $\mathrm{E}_{2}$ level was significantly higher in women with BRCA2 mutations compared to women with BRCA1 mutations or without BRCA mutations ( $71.7 \pm 41.6$ vs. $45.5 \pm 20.7$ vs. $38.5 \pm 12.6 \mathrm{pg} / \mathrm{ml}$ in BRCA2 mutation carriers, BRCA1 mutation carriers, and non-carriers, respectively, $\mathrm{p}$-value $=0.03$ ). Women with BRCA2 mutations had 3.1 times as great risk for high basal $\mathrm{E}_{2}$ level $(>48 \mathrm{pg} / \mathrm{ml})$ as women without BRCA mutations after adjusting for age and BMI (95\% confidence interval: 1.3, 7.6). BRCA mutation carriers with high serum $E_{2}$ level were significantly younger than the carriers with low serum $E_{2}$ level (31.4 \pm 3.1 vs. $34.7 \pm 4.9$ year, $\mathrm{p}=0.04)$.

Conclusions-In this pilot study, we found an association between high basal serum $\mathrm{E}_{2}$ levels and BRCA2 mutations. Our results suggest that increased production of serum $\mathrm{E}_{2}$ may have a role in the pathogenesis of BRCA2-mutation related breast cancer.

\section{Keywords}

BRCA; Breast Cancer; Estradiol

\section{Introduction}

A large number of germline BRCA gene mutations are associated with breast cancer development [1]. The cumulative risk of breast carcinoma in carriers of BRCA mutations ranges from $45 \%$ to $84 \%$ by age $70[2,3]$. BRCA genes are members of the ATM/ATRmediated DNA double strand break (DSB) repair pathway. Germline mutations in one allele and subsequent dysfunction of the intact allele eventually lead to accumulation of impaired DSB repair which in turn results in mutagenesis and carcinogenesis [4]. This mechanism of action however, does not sufficiently explain why BRCA-associated tumors predominantly occur in estrogen-responsive tissues, such as the breast and ovary [5].

*Corresponding Author: koktay@fertilitypreservation.org.

Conflicts of interests

The authors declare they have no conflict of interest. 
Several studies have shown a possible role of estrogen action, another well-known risk factor for breast carcinogenesis, as a risk modifier in BRCA-associated breast cancer. Prophylactic oophorectomy decreases the risk of breast carcinoma in BRCA mutation carriers [6-8], likely due to the profound drop in circulating estrogen after surgery. Tamoxifen decreases the risk of a secondary breast malignancy in BRCA mutation carriers $[9,10]$. However, despite these clinical studies, the role of estrogen action on BRCAmutation associated breast cancer risk modification is not as clear as in sporadic breast cancer.

There is also biologic evidence of interactions between BRCA proteins and estrogen action. First, normal BRCA1 expression can be induced by estrogen exposure in experimental models [11]. Second, the wild-type BRCA1 gene negatively regulates aromatase expression in a human granulosa cell line [12], likely suppressing estrogen production. Finally, although the relationship between the BRCA2 gene function and estrogen metabolism has not been investigated as extensively as it has been with BRCA1, a link was reported between estrogen action and BRCA2 protein function in breast cancer cell lines [13].

Based on the foregoing, we hypothesized an interaction among serum estrogen levels, BRCA mutation status and breast carcinogenesis. To probe this relationship, we evaluated the baseline serum estradiol $\left(\mathrm{E}_{2}\right)$-most potent biologic form of estrogen- levels in breast cancer patients in relationship to BRCA gene mutations. Because serum $\mathrm{E}_{2}$ levels vary throughout the cycle in premenopausal women, we used menstrual cycle day $2 / 3$ measurements which standardizes the assessment of baseline estrogen output [14].

\section{Methods}

We performed a secondary analysis of the prospective COST-LESS ( $\underline{\text { Controlled }}$ Ovarian

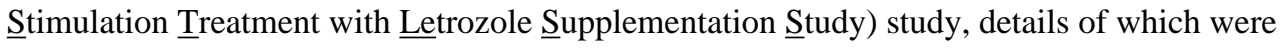
published elsewhere [5]. One hundred consecutive pre-menopausal patients with breast cancer, age 24-44, who were referred for fertility reservation and underwent BRCA testing were included. The exclusion criteria were as follows: evidence of peri-menopause or menopause, medications affecting basal estrogen levels such as the oral contraceptive use within the last 4 weeks, history of ovarian surgery, and prior chemotherapy or radiation therapy.

Continuous data (presented as mean \pm standard deviation) was analyzed by ANOVA, $t$ - test or Kruskal-Wallis test as appropriate. Categorical data was analyzed using $\chi^{2}$ or Fisher's exact tests as appropriate. A two tailed $P<0.05$ was considered statistically significant. To correct for the multiple comparisons, a Bonferroni adjustment was used. Linear regression analysis was used to calculate the risk ratios for high basal $\mathrm{E}_{2}$ levels in groups of patients stratified by BRCA gene mutation status. Statistical analysis was performed with the SAS 9.2 for Windows package (SAS, Cary, NC).

\section{Results}

\section{Patient characteristics}

Of the one hundred women with recent diagnosis of breast cancer who underwent BRCA testing, four who recently used oral contraceptive pills were excluded leaving data from 96 for final analysis. The mean age of the study population was $35.6 \pm 4.8$ years (range, 24 to 44 years). Of those 96 women, 67 (70\%) were negative for BRCA mutations, and 29 (30\%) carried BRCA mutations. Among 29 BRCA mutation carriers, 21 (72\%) patients had BRCA1 mutations and $8(28 \%)$ had BRCA2 mutations. The mean age, parity, BMI, and age at menarche were not different among women with BRCA1, BRCA2 mutations, and without 
BRCA gene mutations (Table 1). The prevalence of having family history of breast/ovarian cancer in the first degree of relatives was higher in women with BRCA2 gene mutations compared to women with BRCA1 mutations and without BRCA mutations (75.0\% vs. $38.1 \%$ vs. $29.3 \%$ in women with BRCA2 mutations, BRCA1 mutations and without BRCA mutations, respectively, $\mathrm{p}=0.04)$. The prevalence of hormone receptor $(\mathrm{ER} a$ and progesterone receptor [PR]) positivity was significantly lower in women with BRCA1 gene mutations compared to women with BRCA2 gene mutations and without BRCA gene mutations (ERa: $35.3 \%$ vs. $100.0 \%$ vs. $92.2 \%, p<0.001$, PR: $25.0 \%$ vs. $100.0 \%$ vs. $81.4 \%$, $p<0.001$ in women with BRCA1 mutations, BRCA2 mutations and without BRCA mutations, respectively.). We encountered a significantly higher proportion of triplenegative breast cancer cases among women with BRCA1 gene mutations compared to those with BRCA2 gene mutations and without BRCA gene mutations (53.3\% vs. $0 \%$ vs. 3.3\%, in women with BRCA1 mutations, BRCA2 mutations and without BRCA mutations, respectively. $p<0.001)$.

\section{Serum $E_{2}$ levels in relationship to BRCA gene mutations}

Basal serum $E_{2}$ levels, which were analyzed from blood drawn on menstrual cycle day $2 / 3$, were significantly higher in women with BRCA2 gene mutations compared to those of women with BRCA1 gene mutations and without BRCA mutations (71.7 \pm 41.6 vs. $45.5 \pm 20.7$ vs. $38.5 \pm 12.6 \mathrm{pg} / \mathrm{ml}$, in women with BRCA2 mutations, BRCA1 mutations and without BRCA mutations, respectively. $p=0.03$. Fig. 1). The association between basal $\mathrm{E}_{2}$ level and BRCA2 gene mutation status remained significant after adjusting the analysis for age and BMI. Basal follicle stimulating hormone levels were not different by BRCA gene mutation status, indicating that the difference in $\mathrm{E}_{2}$ levels was not related to diminished ovarian reserve (data not shown).

When we dichotomized basal $\mathrm{E}_{2}$ levels with a cutoff point of $48 \mathrm{pg} / \mathrm{ml}$, which is the 75th percentile $E_{2}$ value for our study population (high; $E_{2}>48 \mathrm{pg} / \mathrm{ml}$ and low; $E_{2} \leq 48 \mathrm{pg} / \mathrm{ml}$ ), the risk for high basal $\mathrm{E}_{2}$ level for patients with BRCA2 gene mutations was 3.1 times as great as that of patients without BRCA gene mutations after adjusting the analysis for age and BMI (95\% confidence interval: 1.3, 7.6, Table 2).

\section{Patient characteristics by serum $\mathrm{E}_{2}$ level}

Analysis of BRCA mutation carriers by serum $\mathrm{E}_{2}$ level (high; $\mathrm{E}_{2}>48 \mathrm{pg} / \mathrm{ml}$ vs. low; $\mathrm{E}_{2} \leq 48$ $\mathrm{pg} / \mathrm{ml}$ ) revealed that the carriers with high serum $\mathrm{E}_{2}$ levels were significantly younger than the carriers with low serum $\mathrm{E}_{2}$ level and non-carriers (Table 3). The age at menarche was significantly later in carriers with high serum $\mathrm{E}_{2}$ levels compared to those with low serum $\mathrm{E}_{2}(p=0.01$, Table 3$)$. However, the mean age and age at menarche were not different by serum $\mathrm{E}_{2}$ level among non-carriers. Paradoxically, we would expect higher baseline $\mathrm{E}_{2}$ levels in older women as higher $\mathrm{E}_{2}$ levels are associated with lower ovarian reserve due to accelerated follicle growth in the aging ovary [15]. This finding strengthens the association between BRCA status and high estrogen production and excludes the possibility that the difference in $\mathrm{E}_{2}$ levels is related to differences in ovarian reserve.

\section{Discussion}

To our knowledge, this is the first report to demonstrate a possible relationship between serum $\mathrm{E}_{2}$ levels and BRCA gene mutation status in premenopausal women with breast cancer. This relationship appears to be more prominent when BRCA1 and BRCA2 mutations are considered separately. We found that women with BRCA2 mutation had significantly higher $\mathrm{E}_{2}$ levels compared to women without BRCA mutations as well as those with BRCA1 mutations. The $\mathrm{E}_{2}$ level among women with BRCA2 mutations in this study is 
much higher than previously reported early follicular phase $\mathrm{E}_{2}$ level (median: $48 \mathrm{pg} / \mathrm{mL}$, range: 28,101 ) among premenopausal breast cancer patients whose BRCA mutation status was not specified [16]. Interestingly, the mean age of BRCA mutation carriers with high basal $E_{2}$ level were significantly younger than that of BRCA mutation carriers with low basal $\mathrm{E}_{2}$ level and non-carriers. Based on these current findings, one may speculate that higher serum $\mathrm{E}_{2}$ level may be associated with the development of breast cancer in BRCA2 mutation carriers as well as the early-onset of breast cancer in this population.

There are several in vitro and animal studies showing a possible role of BRCA genes in the regulation of $\mathrm{E}_{2}$ synthesis. It has been previously shown that BRCA1 negatively regulates aromatase action [12], and in turn, decreases $\mathrm{E}_{2}$ synthesis. In mice, it was reported that estrogen biosynthesis by granulosa cells was increased not only in mice carrying a homozygous BRCA1 mutation, but also in heterozygous mutants [17]. Bramley et al. reported that BRCA1/2 haploinsufficiency alters the estrogen sensitivity of normal breast epithelium as assessed by proliferation and induction of estrogen-induced genes [18]. A recent animal study showed that loss of BRCA1 gene function increases murine ovarian epithelial tumor predisposition by increasing estrogen stimulation in the absence of progesterone [19].

Interestingly, in a study with cancer-free women aged 35 years or older, tamoxifen reduced breast cancer incidence among healthy BRCA2 carriers, however, had no effect on cancer incidence among healthy BRCA1 carriers [10]. This finding is consistent with the fact that, in humans, the majority of BRCA1-mutation-related breast cancers are ERa negative, and the majority of BRCA2-mutation-related breast cancers are ERa positive [20]. Our results also support the above studies because women with BRCA2 mutations have higher basal $\mathrm{E}_{2}$ levels compared to women without BRCA mutations. A prior in vitro investigation shows that estrogen-induced DNA DSBs is ERa dependent [21]. Given that BRCA genes have critical roles in DNA DSBs repair [22, 23], these previous findings and our finding suggest that BRCA2 mutations may have synergistically reduce DNA DSB repair in the presence of higher $E_{2}$ and $E R a$, and result in the increased risk of developing breast cancer. In our study, the BRCA mutation carriers with high $\mathrm{E}_{2}$ levels were significantly younger than BRCA mutation carriers with low $\mathrm{E}_{2}$ levels and non-carriers. Of note, the mean age of BRCA2 mutation carriers was 32.0 years which tends to be less than that of BRCA1 mutation carriers and non-carriers. These findings may suggest high $\mathrm{E}_{2}$ levels may be the cause of early-onset breast cancer in BRCA2 mutation carriers. When the foregoing is taken together with the data presented here, it may be worth to design studies to test tamoxifen use at a younger age to reduce breast cancer incidence among BRCA2 mutation carriers.

Although several in vitro and animal studies suggest a possible relationship between BRCA1/2 genes and the regulation of $E_{2}$ synthesis [12, 17-19], basal $E_{2}$ levels were higher only in BRCA2 mutation carriers in this study. It was reported that tissue $\mathrm{E}_{2}$ levels are selectively elevated in hormone receptor positive breast cancer [24], and our results show that the prevalence of hormone receptor (ERa and progesterone receptor [PR]) positivity was significantly higher in women with BRCA2 gene mutations. This finding is also consistent with the previous report showing that high serum estrogen level was an independent risk factor of ER (+) breast cancer risk in postmenopausal women [25]. Based on this, it would be interesting to investigate the possible role of the hormone receptor in regulation of serum $\mathrm{E}_{2}$ levels in BRCA mutation carriers.

Our study has several significant clinical implications. First, this is the first study to show a possible association between BRCA2 gene mutations and serum $\mathrm{E}_{2}$ levels as well as a potential synergy between the two in breast cancer pathogenesis. Second, it offers a plausible explanation for the development of BRCA2-related tumors in estrogen-sensitive 
tissues. Third, considering the low prevalence of BRCA gene mutations among general population as well as the difficulty in collecting standardized basal blood samples in an oncology center environment, this is a unique preliminary report generated in the process of fertility preservation evaluation.

There are several limitations in this study. First, the small number of study population does not allow us to make population-level inferences based on our findings. However, we believe that this study provides an appropriate pilot data which would facilitate future larger studies. Second, one might argue about the possibility of bias due to the potential variability of the serum estrogen levels from cycle to cycle and the impact of diagnosis of breast cancer on the hormonal variability. In this study, the potential variability of the serum estrogen levels due to the breast cancer diagnosis was adjusted by collecting all blood samples from those who already developed cancer. Furthermore the measurements were obtained on menstrual cycle day $2 / 3$ which has been well proven to standardize estradiol measurements in ovarian reserve studies. However, it does not seem to be feasible to control the cycle-tocycle variability in serum estrogen levels under the time constraint (usually 2-4 weeks between the diagnosis and the initiation of cancer treatments) in this study population. Further research investigating serum estrogen levels from mutation carriers without breast cancer may offer appropriate controls to address this issue.

In this pilot study, we found an association between high basal serum $\mathrm{E}_{2}$ levels and BRCA2 gene mutations. This is a highly novel and clinically relevant finding since increased baseline $\mathrm{E}_{2}$ levels can be targeted for risk-screening or prevention of breast carcinogenesis in women with BRCA2 gene mutations. Our data suggests that women who carry BRCA2 mutations may benefit from anti-estrogen treatments. To evaluate the role of $E_{2}$ in pathogenesis of breast cancer in BRCA2 mutation carriers, future studies should prospectively determine the association between baseline $\mathrm{E}_{2}$ levels and the risk of breast cancer development in unaffected BRCA2-mutation carriers. Future studies should also focus on the role of $E_{2}$ on the development of BRCA1 mutation-related breast cancers.

\section{Supplementary Material}

Refer to Web version on PubMed Central for supplementary material.

\section{References}

1. Bray F, McCarron P, Parkin DM. The changing global patterns of female breast cancer incidence and mortality. Breast Cancer Res. 2004; 6(6):229-239. [PubMed: 15535852]

2. Antoniou A, Pharoah PD, Narod S, Risch HA, Eyfjord JE, Hopper JL, Loman N, Olsson H, Johannsson O, Borg A, et al. Average risks of breast and ovarian cancer associated with BRCA1 or BRCA2 mutations detected in case Series unselected for family history: a combined analysis of 22 studies. Am J Hum Genet. 2003; 72(5):1117-1130. [PubMed: 12677558]

3. Ford D, Easton DF, Stratton M, Narod S, Goldgar D, Devilee P, Bishop DT, Weber B, Lenoir G, Chang-Claude J, et al. Genetic heterogeneity and penetrance analysis of the BRCA1 and BRCA2 genes in breast cancer families. The Breast Cancer Linkage Consortium. Am J Hum Genet. 1998; 62(3):676-689. [PubMed: 9497246]

4. Zhong Q, Chen CF, Li S, Chen Y, Wang CC, Xiao J, Chen PL, Sharp ZD, Lee WH. Association of BRCA1 with the hRad50-hMre11-p95 complex and the DNA damage response. Science. 1999; 285(5428):747-750. [PubMed: 10426999]

5. Oktay K, Kim JY, Barad D, Babayev SN. Association of BRCA1 mutations with occult primary ovarian insufficiency: a possible explanation for the link between infertility and breast/ovarian cancer risks. J Clin Oncol. 2010; 28(2):240-244. [PubMed: 19996028] 
6. Kauff ND, Satagopan JM, Robson ME, Scheuer L, Hensley M, Hudis CA, Ellis NA, Boyd J, Borgen PI, Barakat RR, et al. Risk-reducing salpingo-oophorectomy in women with a BRCA1 or BRCA2 mutation. N Engl J Med. 2002; 346(21):1609-1615. [PubMed: 12023992]

7. Rebbeck TR, Lynch HT, Neuhausen SL, Narod SA, Van’t Veer L, Garber JE, Evans G, Isaacs C, Daly MB, Matloff E, et al. Prophylactic oophorectomy in carriers of BRCA1 or BRCA2 mutations. N Engl J Med. 2002; 346(21):1616-1622. [PubMed: 12023993]

8. Rebbeck TR, Levin AM, Eisen A, Snyder C, Watson P, Cannon-Albright L, Isaacs C, Olopade O, Garber JE, Godwin AK, et al. Breast cancer risk after bilateral prophylactic oophorectomy in BRCA1 mutation carriers. J Natl Cancer Inst. 1999; 91 (17):1475-1479. [PubMed: 10469748]

9. Fisher B. Highlights from recent National Surgical Adjuvant Breast and Bowel Project studies in the treatment and prevention of breast cancer. CA Cancer J Clin. 1999; 49(3):159-177. [PubMed: 10445015]

10. King MC, Wieand S, Hale K, Lee M, Walsh T, Owens K, Tait J, Ford L, Dunn BK, Costantino J, et al. Tamoxifen and breast cancer incidence among women with inherited mutations in BRCA1 and BRCA2: National Surgical Adjuvant Breast and Bowel Project (NSABP-P1) Breast Cancer Prevention Trial. JAMA. 2001; 286(18):2251-2256. [PubMed: 11710890]

11. Seery LT, Knowlden JM, Gee JM, Robertson JF, Kenny FS, Ellis IO, Nicholson RI. BRCA1 expression levels predict distant metastasis of sporadic breast cancers. Int J Cancer. 1999; 84(3): 258-262. [PubMed: 10371343]

12. Hu Y, Ghosh S, Amleh A, Yue W, Lu Y, Katz A, Li R. Modulation of aromatase expression by BRCA1: a possible link to tissue-specific tumor suppression. Oncogene. 2005; 24(56):8343-8348. [PubMed: 16170371]

13. Malone JL, Nelson AC, Lieberman R, Anderson S, Holt JT. Oestrogen-mediated phosphorylation and stabilization of BRCA2 protein in breast. J Pathol. 2009; 217(3):380-388. [PubMed: 19016568]

14. Lee S, Ozkavukcu S, Heytens E, Moy F, Alappat RM, Oktay K. Anti-Mullerian hormone and antral follicle count as predictors for embryo/oocyte cryopreservation cycle outcomes in breast cancer patients stimulated with letrozole and follicle stimulating hormone. J Assist Reprod Genet. 2011; 28(7):651-656. [PubMed: 21573682]

15. Stovall DW, Toma SK, Hammond MG, Talbert LM. The effect of age on female fecundity. Obstet Gynecol. 1991; 77(1):33-36. [PubMed: 1984224]

16. Eliassen AH, Missmer SA, Tworoger SS, Spiegelman D, Barbieri RL, Dowsett M, Hankinson SE. Endogenous steroid hormone concentrations and risk of breast cancer among premonopausal women. J Nat Cancer Inst. 2006; 98(19):1406-1415. [PubMed: 17018787]

17. Yen HY, Gabet Y, Liu Y, Martin A, Wu NL, Pike MC, Frenkel B, Maxson R, Dubeau L. Alterations in Brcal expression in mouse ovarian granulosa cells have short-term and long-term consequences on estrogen-responsive organs. Lab Invest. 2012; 92 (6):802-811. [PubMed: 22488153]

18. Bramley M, Clarke RB, Howell A, Evans DG, Armer T, Baildam AD, Anderson E. Effects of oestrogens and anti-oestrogens on normal breast tissue from women bearing BRCA1 and BRCA2 mutations. Br J Cancer. 2006; 94(7):1021-1028. [PubMed: 16538216]

19. Hong H, Yen HY, Brockmeyer A, Liu Y, Chodankar R, Pike MC, Stanczyk FZ, Maxson R, Dubeau L. Changes in the mouse estrus cycle in response to BRCA1 inactivation suggest a potential link between risk factors for familial and sporadic ovarian cancer. Cancer Res. 2010; 70(1):221-228. [PubMed: 20028858]

20. Metcalfe K, Lynch HT, Ghadirian P, Tung N, Olivotto I, Warner E, Olopade OI, Eisen A, Weber $\mathrm{B}$, McLennan J, et al. Contralateral breast cancer in BRCA1 and BRCA2 mutation carriers. J Clin Oncol. 2004; 22(12):2328-2335. [PubMed: 15197194]

21. Williamson LM, Lees-Miller SP. Estrogen receptor alpha-mediated transcription induces cell cycle-dependent DNA double-strand breaks. Carcinogenesis. 2011; 32(3):279-285. [PubMed: 21112959]

22. Patel KJ, Yu VP, Lee H, Corcoran A, Thistlethwaite FC, Evans MJ, Colledge WH, Friedman LS, Ponder BA, Venkitaraman AR. Involvement of Brca2 in DNA repair. Mol Cell. 1998; 1(3):347357. [PubMed: 9660919] 
23. Frankish H. BRCA1 has a pivotal role in repairing DNA. Lancet. 2001; 357(9269):1678.

24. Lonning PE, Helle H, Duong NK, Ekse D, Aas T, Geisler J. Tissue estradiol is selectively elevated in receptor positive breast cancers while tumour estrone is reduced independent of receptor status. J Steroid Biochem Mol Biol. 2009; 117(1-3):31-41. [PubMed: 19591931]

25. Farhat GN, Cummings SR, Chlebowski RT, Parimi N, Cauley JA, Rohan TE, Huang AJ, Vitolins M, Hubbell FA, Manson JE, et al. Sex hormone levels and risks of estrogen receptor-negative and estrogen receptor-positive breast cancers. J Natl Cancer Inst. 2011; 103(7):562-570. [PubMed: 21330633] 


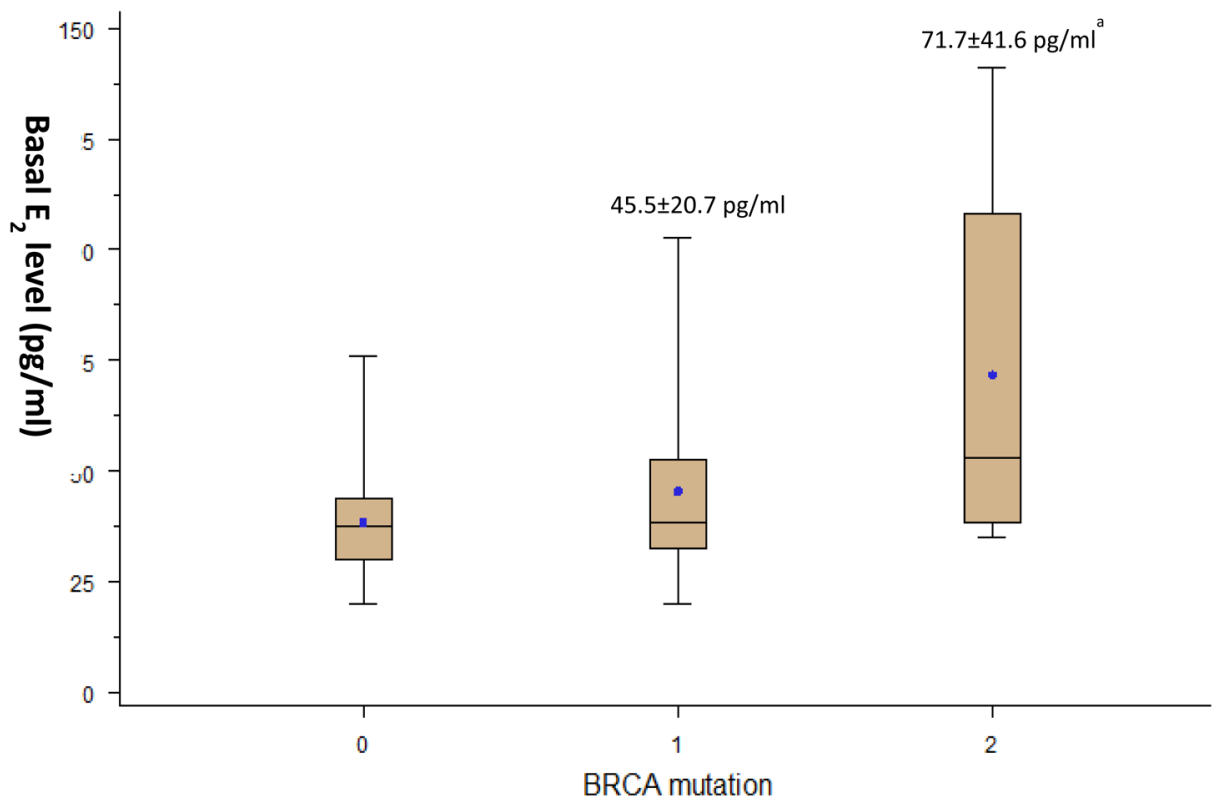

Fig. 1. Comparison of basal serum estradiol $\left(E_{2}\right)$ levels by BRCA mutation status

The upper and lower $\mathrm{T}$ bars denote maximum and minimum values, respectively. The lines inside the plot boxes denote median values and dots denote mean values. The numbers above the upper $\mathrm{T}$ bars denotes "mean baseline serum $\mathrm{E}_{2}$ levels \pm standard deviation" in each group.

${ }^{\mathrm{a}} \mathrm{p}<0.017$ compared to BRCA(-) group analyzed by multiple comparisons with a Bonferroni adjustment 
Table 1

Comparison of clinical characteristics by BRCA mutation status

\begin{tabular}{|c|c|c|c|c|}
\hline & BRCA (-) $(n=67)$ & BRCA1 $(+)(n=21)$ & $\operatorname{BRCA2}(+)(n=8)$ & p-value \\
\hline Age (years) & $35.3 \pm 4.2$ & $34.1 \pm 4.9$ & $32.0 \pm 3.4$ & 0.11 \\
\hline Parity $\geq 1$ & $9.8 \%$ & $15.0 \%$ & $25.0 \%$ & 0.45 \\
\hline $\mathrm{BMI}\left(\mathrm{Kg} / \mathrm{m}^{2}\right)$ & $22.8 \pm 3.4$ & $21.5 \pm 1.7$ & $21.2 \pm 2.0$ & 0.42 \\
\hline Age at menarche (years) & $12.7 \pm 1.6$ & $12.7 \pm 1.6$ & $12.0 \pm 1.9$ & 0.84 \\
\hline Family history of breast/ovarian cancer ${ }^{*}$ & $29.3 \%$ & $38.1 \%$ & $75.0 \%$ & 0.04 \\
\hline History of infertility ${ }^{\dagger}$ & $15.4 \%$ & $15.0 \%$ & $0.0 \%$ & 0.54 \\
\hline \multicolumn{5}{|l|}{ Cancer } \\
\hline Stage & & & & 0.46 \\
\hline \II & $94.5 \%$ & $93.3 \%$ & $80.0 \%$ & \\
\hline III & $5.5 \%$ & $6.7 \%$ & $20.0 \%$ & \\
\hline $\mathrm{ERa}$ & $92.2 \%$ & $35.3 \%$ & $100.0 \%$ & $<0.001$ \\
\hline PR & $81.4 \%$ & $25.0 \%$ & $100.0 \%$ & $<0.001$ \\
\hline Her $2 /$ neu & $34.0 \%$ & $14.3 \%$ & $40.0 \%$ & 0.33 \\
\hline Triple-negative & $3.3 \%$ & $53.3 \%$ & $0.0 \%$ & $<0.001$ \\
\hline $\begin{array}{l}\text { Abbreviation: ERa, estrogen receptor } a ; P F \\
* \\
\text { History of breast/ovarian cancer in first-de }\end{array}$ & $\begin{array}{l}\text {, progesterone recep } \\
\text { gree relatives }\end{array}$ & & & \\
\hline
\end{tabular}


Table 2

Risk ratios for high level of basal $\mathrm{E}_{2}(>48 \mathrm{pg} / \mathrm{ml})$

\begin{tabular}{lcc}
\hline & Risk Ratio $^{\boldsymbol{a}}$ & $\mathbf{9 5 \%}$ Confidence Interval \\
\hline Patients with BRCA gene mutation (n=29) & 2.3 & $1.1-4.9$ \\
Patients with BRCA1 gene mutation (n=21) & 2.3 & $1.0-5.6$ \\
Patients with BRCA2 gene mutation (n=8) & 3.1 & $1.3-7.6$ \\
\hline Abbreviation: E2, estradiol & \\
a Risk ratio for high level of basal E2 compared to patients without BRCA gene mutations after adjusting for age and BMI
\end{tabular}




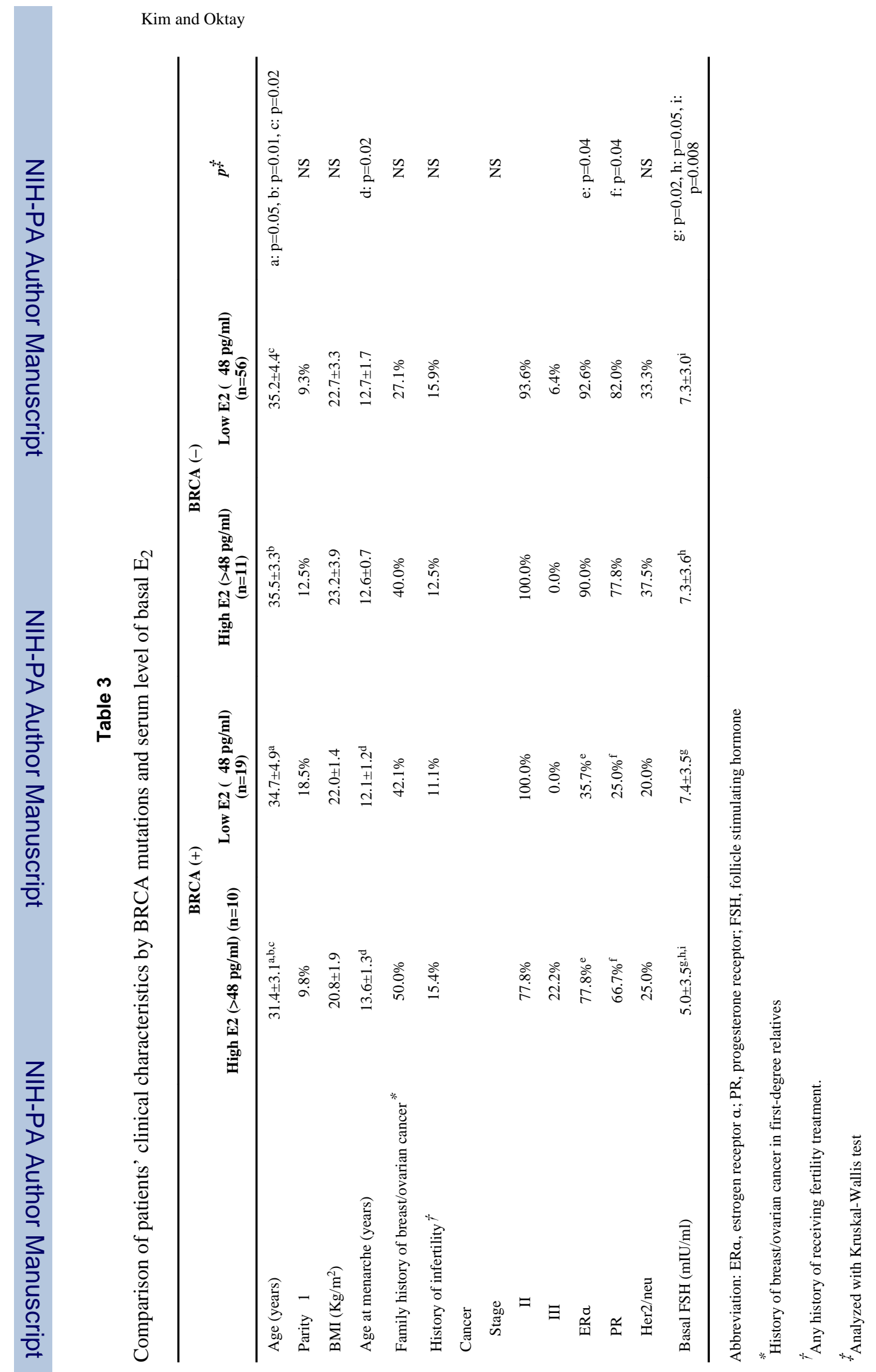

Cancer Causes Control. Author manuscript; available in PMC 2014 March 01. 